\title{
Study on the Improved Severity Coefficient Model of Dam Break Consequence Assessment
}

\author{
Weiwei Sun ${ }^{1,2}$, Qian Cai ${ }^{1,2}$, Zhifei Long ${ }^{1,2}$ \\ ${ }^{1}$ Dam Safety Management Department, Nanjing Hydraulic Research Institute, Nanjing, China \\ ${ }^{2}$ Dam Safety Management Center of the Ministry of Water Resources, Nanjing, China
}

Email address:

wwsun@nhri.cn (Weiwei Sun), wizertize@foxmail.com (Qian Cai), long.zhifei@163.com (Zhifei Long)

\section{To cite this article:}

Weiwei Sun, Qian Cai, Zhifei Long. Study on the Improved Severity Coefficient Model of Dam Break Consequence Assessment. American Journal of Civil Engineering. Vol. 9, No. 3, 2021, pp. 84-90. doi: 10.11648/j.ajce.20210903.14

Received: April 16, 2021; Accepted: June 8, 2021; Published: June 10, 2021

\begin{abstract}
The assessment of the dam failure consequences is fundamental to the dam risk assessment, and the linear weight sum method is generally used. The comprehensive evaluation of dam failure consequences involves many evaluation factors, the dimensions of each factor are inconsistent. The key is to determine the coefficient of the severity degree of dam failure consequences. Based on the traditional methods, a new severity degree coefficient model of the loss of life, economic losses, environmental impact, and social impact is established after taking the current laws and regulations, the range of the severity of the impact, the establishment of normalized function, the introduction of piecewise function and other factors into comprehensive consideration, and use analysis hierarchy process to obtain weight. Apply the improved linear weighting method to the level assessment and rank of the dam failure consequences of Changlong reservoir, Xialan reservoir, Shibikeng reservoir, Longshan reservoir and Lingtan reservoir in Jiangxi Province, and then determine the grade and rank of dam failure consequences according to the calculation results, analyze the corresponding results accurately combined with expertise. The evaluation results and analysis show that if dam failure occurs, the consequences of the five dams are all very serious, it belongs to extraordinarily serious accidents. The severity degree coefficient of dam failure consequences model can reflect the severity degree of dam failure consequences more objectively and reasonably, and it has clear concept, simple calculation, and intuitive process.
\end{abstract}

Keywords: Dam Risk, Dam Failure Consequences, Severity Coefficient, Improved Model, Linear Weight Sum Method

\section{Introduction}

The comprehensive assessment of the dam failure consequences is fundamental to the dam risk assessment. According to the «Report on production safety accident and regulations of investigation and treatment» (Order No. 493 of the State Council of the People's Republic of China on March 28, 2007), the accident levels are divided into ordinary accidents, larger accidents, major accidents and extraordinarily serious accidents. Therefore, comprehensive assessment of dam failure consequences is especially important in the application of risk ranking order of dams danger removal and reinforcement.

The comprehensive assessment of the dam failure consequences is a complex system [1], it involves many evaluation factors, such as the loss of life, economic losses, environmental impact and social impact which caused by dam failure, and the dimensions of each factor are inconsistent [2]. Li Shouyi et al. [3] based on the variable fuzzy set theory, combined with the analytic hierarchy process to determine the weight of each evaluation index, and established a comprehensive evaluation model for the consequences of a dam failure based on the variable fuzzy set theory. Chen Yue et al. [4] constructed a comprehensive evaluation function of the consequences of a dam break by using a linear weighting method, used a risk matrix to judge the risk area of the dam, and used the Borda sequence value method to sort the dams to remove dangers and strengthen them, and establish a risk assessment of the consequences of a dam break model. Li Zongkun et al. [5] established a comprehensive evaluation model for the consequences of a dam failure based on set pair analysis, and determined the risk evaluation level based on the principle of maximum set pair potential. According to the «Guidelines for emergency preparedness plan of reservoir dam safety management» (SL/Z 720-2015) which is issued by the Ministry of Water Resources, the severity of the dam failure consequences is divided into four levels: accidents that cause more than 30 deaths or serious injuries of more than 100 people 
(including acute industrial poisoning, the following is same), or direct economic losses of more than 100 million yuan (RMB, The same below), are classified as level I (extraordinarily serious); Accidents that cause more than 10 deaths but less than 30 deaths, or serious injuries of more than 50 people but less than 100 people, or direct economic losses of more than 50 million yuan but less than 100 million yuan, are classified as level II (major); Accidents that cause more than 3 deaths but less than 10 deaths, or serious injuries of more than 10 people but less than 50 people, or direct economic losses of more than 10 million yuan but less than 50 million yuan, are classified as level III (larger); Accidents that cause less than 3 deaths, or serious injuries of less than 10 people, or direct economic losses of less than 10 million yuan, are classified as level IV (ordinary). It shows that the loss of life and economic losses are controlled by standards, and they have corresponding quantitative control index [6], but the environmental impact and social impact have no quantitative index. Conventional comprehensive multi-index assessment method [7-8] generally refers to linear weighting method, this method neither use fuzzy method to deal with multi-index comprehensive assessment nor consider how to eliminate the important information of the difference between the indicators in the assessment transformation, instead it uses general mathematical method to nondimensionalize and synthetic processing. In the conventional comprehensive multi-index assessment method, nondimensionalization is a crucial step, which requires special treatment [9], therefore, it is necessary to conduct in-depth discussion and research on the construction of the dam-break consequence severity coefficient model.

\section{Linear Weighting Comprehensive Assessment Method}

\subsection{Fundamental}

Linear weighting method, also be called as additive synthesis or weighted arithmetic averaging operator, it refers to the application of linear models for comprehensive assessment [10]:

$$
L=\sum_{j=1}^{m} w_{j} F_{j}
$$

In the formula: $L$ is the comprehensive assessment value of the system or the assessed object, $w_{j}$ is the weight coefficient corresponding to the assessment index $F_{j}$ $\left(0 \leq w_{j} \leq 1(j=1,2, \cdots, m), \sum_{j=1}^{m} w_{j}=1\right)$.

\subsection{Traditional Severity Degree Coefficient of Dam Failure Consequences}

According to the coefficient assignment reference table of the loss of life, economic losses, environmental impact and social impact that graded by Li Lei et al. in the book $<<$ Dam Risk Assessment and Risk Management $>>[11]$, the specific qualitative classification of the comprehensive evaluation about dam-break event is shown in the table 1 .

Table 1. Comprehensive evaluation control table about dam-break event.

\begin{tabular}{lllll}
\hline \multirow{2}{*}{ Indicator } & A & B & C & D \\
\cline { 2 - 5 } & Ordinary accidents & Lager accidents & Major accidents & Extraordinarily serious accidents \\
\hline $\mathrm{F}_{1}$ The loss of life/person & $1-3$ & $3-10$ & $10-30$ & $30-100000$ \\
$\mathrm{~F}_{2}$ Economic losses/ten thousand yuan & $10-1000$ & $1000-5000$ & $5000-10000$ & $10000-1000000$ \\
$\mathrm{~F}_{3}$ Environmental impact coefficient & $1-3$ & $3-8$ & $8-25$ & $25-100$ \\
$\mathrm{~F}_{4}$ Social impact coefficient & $1-3$ & $3-12$ & $12-40$ & $40-100$ \\
\hline
\end{tabular}

Li Lei et al. once introduced comprehensive evaluation function of dam failure consequences [12-14], and further proposed the severity coefficient model as follows:

(1) Severity degree coefficient of the loss of life $F_{1}$

$$
F_{1}=\frac{1}{5^{0.1}}(\lg x)^{0.1}
$$

In the formula: $x$ represents the number of the loss of life (person)

Establishing this model is mainly to control the severity degree coefficient values of 3 persons, 10 persons, and 50 persons. Using this model to calculate, when the loss of life is 3 persons, the severity has exceeded 0.6 ; when the loss of life is 10 persons, the severity has exceeded 0.7 ; and when the loss of life is 50 persons, the severity is 0.9 , which is considered to be compared with the policy norm.

(2) Severity degree coefficient of economic losses $F_{2}$

$$
F_{2}=\frac{1}{5^{0.2}}\left(\lg \frac{x}{10}\right)^{0.2}
$$

In the formula: $x$ represents the number of economic losses (ten thousand yuan).

Establishing this model is mainly to consider the boundaries of 300,000 yuan, 1 million yuan, 3 million yuan and 10 million yuan. Considering that the importance of life is higher than that of economy, so the corresponding life loss model index is selected as 0.1 , and the economic loss model index is selected as 0.2 .

(3) Severity degree coefficient of social environmental impact $F_{3}$

$$
F_{3}=\frac{1}{4} \lg f
$$

In the formula: frepresents environmental impact coefficient. Establishing model is mainly to consider that when it doesn't have law or specification stipulate what kind of impact is ordinary, major, and extraordinarily serious, the importance 
is linear, and it increases with the increase of the social environmental impact coefficient.

According to the model, the weight coefficients of the loss of life, economic losses, and social and environmental impacts are selected as $0.737,0.105$, and 0.158 respectively. Based on this, the severity degree coefficient and the comprehensive coefficient on the control point of the dam-break event can be obtained, it is shown in the table 2 . When $\mathrm{L}<0.6672$, it is a ordinary accident; when $0.6672 \leq \mathrm{L}<0.7430$, it is a larger accident; when $0.7430 \leq \mathrm{L}<0.7930$, it is a major accident; when $\mathrm{L} \geq 0.7930$, it is a extraordinarily serious accident and it should be reported to the State Council immediately. It can use 0.6672 , 0.7430 , and 0.7930 as control indicators.

Table 2. The serious coefficient and comprehensive coefficient on dam-break events control points with Li lei method.

\begin{tabular}{llll}
\hline Control Element & $\begin{array}{l}\text { Severity } \\
\text { degree } \\
\text { coefficient of } \\
\text { the loss of life }\end{array}$ & $\begin{array}{l}\text { Severity degree } \\
\text { coefficient of } \\
\text { economic losses }\end{array}$ & $\begin{array}{l}\text { Severity degree } \\
\text { coefficient of social } \\
\text { and environmental } \\
\text { imapct }\end{array}$ \\
\hline $\begin{array}{l}\text { Evaluation coefficient corresponding to 3 people and 300,000 yuan } \\
\text { coefficient of dam } \\
\text { failure consequences }\end{array}$ & $\begin{array}{l}0.7906 \\
\text { Evaluation coefficient corresponding to 10 people and 1,000,000 yuan }\end{array}$ & 0.6513 & 0.1193 \\
Evaluation coefficient corresponding to 30 people and 3,000,000 yuan & 0.8852 & 0.7248 & 0.25 \\
\hline
\end{tabular}

Annotations: In the calculation, the weight coefficients S1, S2, and S3 are 0.737, 0.105, and 0.15

\section{Improvement of the Severity Degree Coefficient of Dam Failure Consequences}

\subsection{Problems of the Traditional Severity Degree model}

The deep analysis of the traditional severity degree coefficient shows that the section of the three indicators corresponding to the four accident levels in Table 2 are very different. For example, corresponding to the highest accident level, the severity degree coefficient of the loss of life varies from 0.8852 to 1 , and the range is 0.1148 . The severity degree coefficient of economic losses varies from 0.7836 to 1 , and the range is 0.2164 ; The severity degree coefficient of social and environmental impact varies from 0.3693 to 1 , and the range is 0.6307 . According to the characteristics of the model, it can be seen as that when the loss of life is 50 people, the severity degree is 0.9 , and when the upper limit is 100,000 , the severity is 1 . Therefore, when use this model to calculate, if the loss of life exceeds 50 people, the severity degree coefficient is little changed.

The economic losses model [15] has the same problem; The highest accident level variation of the social and environmental impact changes is 0.6307 , which excessively widens the gap between the severity of the different coefficients. When this model is used for comprehensive evaluation, it will make the comprehensive assessment coefficient mainly depend on the social and environmental impact, and it cannot reflect the status of the loss of life and economic losses in the comprehensive assessment. Moreover, the control points of 300,000 yuan, 1 million yuan, and 3 million yuan in the economic losses severity degree coefficient model are in line with the policy and regulations at the time. However, with the development of the economy, the current policy and regulations have increased the control points to 10 million yuan, 50 million yuan and 100 million yuan. Therefore, there are many irrationals in this severity degree coefficient model with comprehensive analysis.

\subsection{Improvement of the Traditional Severity Degree model}

Based on the research of Li Lei et al. on the comprehensive evaluation function of dam failure consequences, and in order to make the severity degree coefficient model more objective and reasonable, this paper consider the following factors:

The variation range of current laws, regulations, and severity of impacts. The loss of life is measured in the number of people, the economic losses is measured in millions of yuan, and the environmental impact and social impact are described by assignment coefficients, such as ordinary, large, major, extraordinarily serious, and so on. For the unity of comparison, normalization is required. According to the current laws and regulations, with specific reference to the "Report on production safety accident and regulations of investigation and treatment" dated March 28, 2007 of the State Council of the People's Republic of China No. 493, combined with specific assignments, it can be considered that the upper limit of the loss of life is 100000 people, divide $1 \sim 100000$ people into 4 levels, namely 1 3 people, 3 10 people, 10 30 people, 30 100,000 people; The upper limit of economic losses is 10 billion yuan, and divide 100,000 10 billion yuan into 4 levels, namely 100,000 10 million yuan, 10 million $\sim 50$ million yuan, 50 million 100 million yuan, 100 million 10 billion yuan; The upper limit of the environmental impact assignment coefficient is 100 , and divide $1 \sim 100$ into 4 levels, namely $1 \sim 3$, $3 \sim 8,8 \sim 25,25 \sim 100$; Similarly, the upper limit of the social impact assignment coefficient is 100, and divide $1 \sim 100$ into 4 levels, namely 1 3, 3 12, 12 40, 40 100.

Normalized function model. Normalize the severity degree of the loss of life, economic losses, environmental impact, and social impact, using mathematically simple and feasible compound function curve characteristics [16] and current policy and specifications, and the severity degree coefficients that meet the quantitative control points should be $0.25,0.5$ and 0.75 , respectively, to make the variation of the four indicators in the four accident level intervals comparatively even, in order to ensure that the comprehensive assessment of the dam failure consequences can thoroughly reflect the severity degree coefficients of these four indicators. 
Introduce piecewise function. According to the policy, the changes of life loss (person) and economic loss (10,000 yuan) in the ordinary accidents, larger accidents, and major accidents are gradual and slow, while the level of extraordinarily serious accidents which is 30 to 100,000 people, 10,000 to 10 million yuan has a rapidly changing upward trend, so it is more reasonable to adopt piecewise function to construct the model of the severity degree coefficient of the loss of life and economic losses. Taking 30 people and 100 million yuan as the demarcation point, because the changes are even when accident level is below 30 people, below 100,000,000 yuan, and the function curve and model calculation formula can be obtained through fitting. Moreover, for the loss of life, although the policy stipulates 30 to 100,000 people as a level, the function curve of the severity degree coefficient model rises fast before 1000 , and tend be stable after 1000 in the range of 30 to 100,000 people, because of the typical data of eight collapsed reservoirs that have experienced significant loss of life which was acquired through Zhou Kefa's investigation [17]. And the sensitivity of the number of deaths. Do the same with the severity degree coefficient model of economic losses.

Taking the above factors into consideration, the study constructs the following improved model for calculating the severity degree coefficient of dam break consequences:

(1) Severity degree coefficient of the loss of life $F_{1}$

$$
F_{1}=\left\{\begin{array}{cc}
0.4997 \lg x+0.008 & x \leq 30 \\
-0.0321 \lg ^{2} x+0.2802 \lg x+0.4023 & x>30
\end{array}\right.
$$

In the formula: $x$ represents the number of the loss of life (person)

(2) Severity degree coefficient of economic losses $F_{2}$

$$
F_{2}=\left\{\begin{array}{cc}
0.4728 \lg ^{2} x-0.9184 \lg x+0.6956 & x \leq 100 \\
0.125 \lg x+0.5 & x>100
\end{array}\right.
$$

In the formula: $x$ represents the number of economic losses (ten thousand yuan)

(3) Severity degree coefficient of environmental impact $F_{3}$

$$
F_{3}=0.4732 \lg x+0.0644
$$

In the formula: $x$ represents environmental impact coefficient.
(4) Severity degree coefficient of social impact $F_{3}$

$$
F_{3}=0.4732 \lg x+0.0644
$$

In the formula: $x$ represents social impact coefficient.

\subsection{Determination of the Weight Coefficient}

Use analytic hierarchy process [18] to determine the weight coefficient of the loss of life, economic losses, environmental impact, and social impact. The importance ratio is $7: 1: 1.5: 1.5$, namely, the weight of the loss of life is 0.636 , the weight of economic losses is 0.091 , the weight of environmental impact is 0.136 , and the weight of social impact is 0.136 , which is comparatively reasonable.

\subsection{Improved Linear Weighting Method}

Based on the above improved severity degree coefficient of the dam failure consequences, linear weighting method of comprehensive evaluation of the dam risk consequences $\mathrm{L}$ is:

$$
L=\sum_{j=1}^{4} w_{j} F_{j}=0.636 F_{1}+0.091 F_{2}+0.136 F_{3}+0.136 F_{4}
$$

In the formula: $F_{1}, F_{2}, F_{3}, F_{4}$ are the loss of life, economic losses, environmental impact, social impact severity degree coefficient, respectively, $w_{j}$ is the corresponding weight coefficient.

\subsection{Evaluation Criterion for the Dam Failure Consequences}

According to the linear weighted comprehensive method to calculate the four grade parameters of the loss of life, economic losses, environmental impact, social impact, and the evaluation model of the severity degree coefficient of dam failure consequences, the four types consequence weights of the dam failure which are determined by the analytic hierarchy process and the evaluation criteria for the dam failure consequences that is formulated by the linear weighted synthesis method are shown in Table 3. It can be considered that when the linear weighted synthesis method is used, if $\mathrm{L}<0.2550$, it is a general accident; If $0.2550 \leq \mathrm{L}<0.5085$, it is a

\begin{tabular}{|c|c|c|c|c|c|}
\hline Accident level & $\begin{array}{l}\text { Severity degree } \\
\text { coefficient of the loss of } \\
\text { life }\end{array}$ & $\begin{array}{l}\text { Severity degree } \\
\text { coefficient of } \\
\text { economic losses } \\
\end{array}$ & $\begin{array}{l}\text { Severity degree } \\
\text { coefficient of } \\
\text { environmental impact }\end{array}$ & $\begin{array}{l}\text { Severity degree } \\
\text { coefficient of } \\
\text { social impact } \\
\end{array}$ & $\begin{array}{l}\text { Comprehensive } \\
\text { assessment coefficient of } \\
\text { dam failure consequences }\end{array}$ \\
\hline Ordinary accidents & $0-0.2464$ & $0-0.2500$ & $0-0.2902$ & $0-0.2653$ & $0-0.2550$ \\
\hline Larger accidents & $0.2464-0.5077$ & $0.2500-0.5000$ & $0.2902-0.4917$ & $0.2653-0.5382$ & $0.2550-0.5085$ \\
\hline Major accidents & $0.5077-0.7461$ & $0.5000-0.7500$ & $0.4917-0.7259$ & $0.5382-0.7752$ & $0.5085-0.7469$ \\
\hline $\begin{array}{l}\text { Extraordinarily } \\
\text { serious accidents }\end{array}$ & $0.7461-1$ & $0.7500-1$ & $0.7259-1$ & $0.7752-1$ & $0.7469-1$ \\
\hline
\end{tabular}
larger accident; if $0.5085 \leq \mathrm{L}<0.7469$, it is a major accident; if $\mathrm{L} \geq 0.7469$, it is a extraordinarily serious accident. It can use $0.2550,0.5085$, and 0.7469 as control indicators, respectively.

Table 3. The evaluation criteria of dam risk consequences based on the Linear weighted method.

Annotations: In the calculation, the weight coefficients of the loss of life, economic losses, environmental impact, social impact are $0.737,0.105$, and 0.158 , respectively. 


\section{Case Application Study}

Take the five reservoir dams of Changlong, Xialan, Shibikeng, Longshan and Lingtan in Jiangxi Province as examples for research, and by means of field visit, the loss of life, economic losses, environmental impact, and social impact of the five reservoir dams are shown in Table 4.

Table 4. Dam break loss data of five reservoirs.

\begin{tabular}{llllll}
\hline The name of the reservoir & Changlong & Xialan & Shibikeng & Longshan & Lingtan \\
\hline The loss of life (person) & 454 & 735 & 975 & 887 & 1709 \\
Economic losses (100 million yuan) & 35 & 25 & 41 & 25 & 20 \\
Environmental impact (coefficient) & 1.43 & 1.43 & 1.43 & 1.43 & 1.43 \\
Social impact (coefficient) & 19.28 & 13.82 & 9.68 & 34.85 & 7.71 \\
\hline
\end{tabular}

\subsection{Determining the Severity Degree Coefficient of the Dam Failure Consequences}

evaluation model about the severity degree coefficient $F_{i}$ of the dam failure consequences of the loss of life, economic losses, environmental impact, and social impact, and they are

The five reservoir dams' severity degree coefficients of dam failure consequences were calculated by the improved shown in Table 5.

Table 5. The serious coefficient on the dam-break consequences of five dams.

\begin{tabular}{lllll}
\hline The name of the reservoir & Changlong & Xialan & Shibikeng & Longshan \\
\hline Severity degree coefficient of the loss of life $\mathrm{F}_{1}$ & 0.9202 & 0.9417 & 0.9530 & 0.9494 \\
Severity degree coefficient of economic losses $\mathrm{F}_{2}$ & 0.9431 & 0.9248 & 0.9516 & 0.9726 \\
Severity degree coefficient of environmental impact $\mathrm{F}_{3}$ & 0.1379 & 0.1379 & 0.1379 & 0.9127 \\
Severity degree coefficient of social impact $\mathrm{F}_{4}$ & 0.6725 & 0.6041 & 0.5309 & 0.1379 \\
\hline
\end{tabular}

\subsection{Evaluation Results Using Linear Weighted Comprehensive Evaluation Method}

According to the severity degree coefficient value of dam failure consequences $F_{i}$ of the five reservoirs in Jiangxi and the weights of the four types dam failures consequences which are determined by the analytic hierarchy process, and compared with the comprehensive standard of dam failure consequences based on the linear weighted synthesis method, this paper use the linear weighted synthesis method to evaluate the dam failure consequences of the five reservoir in Jiangxi, and the results are shown in Table 6.

Table 6. Comprehensive evaluation results on the dam-break consequences of five dams based on the Linear weighted method.

\begin{tabular}{lllll}
\hline Linear weighted method & Changlong & Xialan & Shibikeng & Longshan \\
\hline $\begin{array}{l}\text { Comprehensive evaluation coefficient } \\
\text { of dam failure consequences L }\end{array}$ & 0.7813 & 0.7840 & 0.7837 & 0.8147 \\
$\begin{array}{l}\text { Comprehensive evaluation results } \\
\text { Extraordinarily } \\
\text { serious accident }\end{array}$ & $\begin{array}{l}\text { Extraordinarily } \\
\text { serious accident }\end{array}$ & $\begin{array}{l}\text { Extraordinarily } \\
\text { serious accident }\end{array}$ & $\begin{array}{l}\text { Extraordinarily } \\
\text { serious accident }\end{array}$ & $\begin{array}{l}\text { Extraordinarily } \\
\text { serious accident }\end{array}$ \\
\hline
\end{tabular}

Annotation: Classify the five dam accident levels based on the standards in Table 3.

It can be seen from the evaluation results combined with the evaluation criteria of the linear weighted comprehensive method that if the five reservoir dams analyzed above break, and the comprehensive consequences are very serious, it should be an extraordinarily serious accident, and should be eliminated and reinforced as soon as possible. According to the linear weighted comprehensive method, the higher the value of the comprehensive evaluation coefficient of the dam failure consequences, the more serious the dam failure consequences. Therefore, the severity of the dam failure consequences of the five reservoir dams is sorted as follows: Longshan $>$ Lingtan $>$ Xialan $>$ Shibikeng $>$ Changlong.

\subsection{Rational Analysis of the Evaluation Results}

First, analyze the accident level, and from Table 7, it can be seen as that the loss of life and economic losses of the five reservoirs are all extraordinarily serious accidents. Accident levels that the environmental impact and social impact belong to have ordinary accidents, larger accidents, and major accidents, but for the comprehensive evaluation of the dam failure consequences, the weight of the loss of life and economic losses is $0.636+0.091=0.727$. Therefore, analyze the data of the dam failure consequences of the five reservoirs intuitively, to meet the reality, it should be extraordinarily serious accidents.

Secondly, analyze the rank of the dam failure consequences of the five reservoirs, and it can be seen from Table 7 that the environmental impact coefficients of the five reservoirs are consistent, so the rank of the other three indicators is mainly considered.

The comprehensive rank of Longshan Reservoir's dam failure consequences is 1 , and the single rank of the loss of life, economic losses, and social impact are 3, 5, and 1, respectively. This is because that although the first two ranks are 3 and 5, 887 far exceeds the lower limit of 30 people for a extraordinarily serious accident level, and for people's 
sensitivity, the loss of life of 887 people is close to 1,000 , which is already very serious and unacceptable; The 2.5 billion yuan economic losses and the 4.1 billion yuan of Shibikeng that ranked first far exceed the lower limit of 100 million yuan, so their severity gap is not very larger; But its social impact coefficient is 34.85 and it is close to the lower limit of 40 , but it varies greatly with the 7.71 of Lingtan Reservoir which is a extraordinarily serious accident and rank 5. Therefore, its final comprehensive rank is first.

Table 7. The rationality analysis on comprehensive evaluation results on the dam-break consequences of five dams.

\begin{tabular}{|c|c|c|c|c|c|}
\hline The name of the reservoir & Changlong & Xialan & Shibikeng & Longshan & Lingtan \\
\hline The loss of life (person) & $454>30$ & $735>30$ & $975>30$ & $887>30$ & $1709>30$ \\
\hline $\begin{array}{l}\text { Accident level } \\
\text { Severity degree coefficient } \\
\text { Single rank }\end{array}$ & $\begin{array}{l}\text { Extraordinarily } \\
\text { serious accident } \\
0.9202 \\
(5)\end{array}$ & $\begin{array}{l}\text { Extraordinarily } \\
\text { serious accident } \\
0.9417 \\
\text { (4) }\end{array}$ & $\begin{array}{l}\text { Extraordinarily } \\
\text { serious accident } \\
0.9530 \\
(2)\end{array}$ & $\begin{array}{l}\text { Extraordinarily } \\
\text { serious accident } \\
0.9494 \\
\text { (3) }\end{array}$ & $\begin{array}{l}\text { Extraordinarily } \\
\text { serious accident } \\
0.9726 \\
\text { (1) }\end{array}$ \\
\hline Economic losses (100 million yuan) & $35>1$ & $25>1$ & $41>1$ & $25>1$ & $20>1$ \\
\hline $\begin{array}{l}\text { Accident level } \\
\text { Severity degree coefficient } \\
\text { Single rank }\end{array}$ & $\begin{array}{l}\text { Extraordinarily } \\
\text { serious accident } \\
0.9431 \\
\text { (2) }\end{array}$ & $\begin{array}{l}\text { Extraordinarily } \\
\text { serious accident } \\
0.9248 \\
\text { (3) }\end{array}$ & $\begin{array}{l}\text { Extraordinarily } \\
\text { serious accident } \\
0.9516 \\
\text { (1) }\end{array}$ & $\begin{array}{l}\text { Extraordinarily } \\
\text { serious accident } \\
0.9248 \\
\text { (5) }\end{array}$ & $\begin{array}{l}\text { Extraordinarily } \\
\text { serious accident } \\
0.9127 \\
(3)\end{array}$ \\
\hline Environmental impact (coefficient) & $1.43<3$ & $1.43<3$ & $1.43<3$ & $1.43<3$ & $1.43<3$ \\
\hline Accident level & Ordinary accident & Ordinary accident & Ordinary accident & Ordinary accident & Ordinary accident \\
\hline Severity degree coefficient & 0.1379 & 0.1379 & 0.1379 & 0.1379 & 0.1379 \\
\hline Single rank & same & same & same & same & same \\
\hline Environmental impact (coefficient) & $19.28<40$ & $13.82<40$ & $9.68<12$ & $34.85<40$ & $7.71<12$ \\
\hline Accident level & Major accident & Major accident & Larger accident & Major accident & Larger accident \\
\hline Single rank & (2) & (3) & (4) & (1) & $(5)$ \\
\hline $\begin{array}{l}\text { Accident level of the dam failure } \\
\text { consequences } \\
\text { Comprehensive evaluation coefficient } \\
\text { rank }\end{array}$ & $\begin{array}{l}\text { Extraordinarily } \\
\text { serious accident } \\
0.7813 \\
(5)\end{array}$ & $\begin{array}{l}\text { Extraordinarily } \\
\text { serious accident } \\
0.7840 \\
\text { (3) }\end{array}$ & $\begin{array}{l}\text { Extraordinarily } \\
\text { serious accident } \\
0.7837 \\
\text { (4) }\end{array}$ & $\begin{array}{l}\text { Extraordinarily } \\
\text { serious accident } \\
0.8147 \\
\text { (1) }\end{array}$ & $\begin{array}{l}\text { Extraordinarily } \\
\text { serious accident } \\
0.7862 \\
\text { (2) }\end{array}$ \\
\hline
\end{tabular}

The comprehensive rank of Lingtan Reservoir's dam failure consequences is 2 , and its single rank of the loss of life, economic losses, and social impact are 1,3, and 5 respectively. This is mainly because that its social impact coefficient 7.71 is too small, and there is an enormous gap between it and 34.85 of Longshan Reservoir, which ranks first, while the economic loss of the five reservoirs is already very large, so the severity gap is not too large, but 1,709 loss of life rank first, so the final comprehensive rank is second.

The comprehensive rank of Xialan Reservoir's dam failure consequences is 3 , and its single rank of the loss of life, economic losses, and social impact are 4, 3, and 3 respectively. This is mainly because that its social impact coefficient is 13.28 and it belongs to major accident, meanwhile that of Shibikeng Reservoir which ranks fourth is 9.68 belongs to larger accident. They are not in the same accident range, so the severity degree coefficient is larger than the loss of life and economic losses, therefore, its final comprehensive rank is third.

The comprehensive rank of Shibikeng Reservoir's dam failure consequences is 4 , and its single rank of the loss of life, economic losses, and social impact are 2, 1, and 4 respectively. Compared with the three reservoirs above, it can be seen as that, its social impact coefficient is 9.68 so it belongs to major accident, moreover it and the three reservoirs above are not in the same range, and they are very different. Therefore, its final comprehensive rank is fourth.

The comprehensive rank of Changlong Reservoir's dam failure consequences is 5, and its single rank of the loss of life, economic losses, and social impact are 5,2, and 2 respectively.
Compared with Shibikeng Reservoir, its social impact is 19.28 and it belongs to major accident and rank second, but 454 loss of life only half of the Shibikeng Reservoir, its rank must be located after the Shibikeng Reservoir. Therefore, its final comprehensive rank is fifth.

In summary, using linear weighting method to comprehensively evaluate the dam failure consequences of the five reservoirs can consider the four indicators that the loss of life, economic losses, environmental impact, and social impact comprehensively, reflecting the comprehensive effect, and the severity degree coefficient model is more reasonable. It is believed that the rank result is reasonable and basically conforms to the objective reality.

\section{Conclusion}

Linear weighting method is an effective and frequently-used method to evaluate dam failure consequences, and the key is to determine the severity degree coefficient of dam failure consequences. Based on the traditional severity degree model, this paper comprehensively considers the variation ranges of four types of accidents corresponding to the loss of life, economic losses, environmental impact and social impact, and the severity degree coefficient that meet the principle that quantitative control points should be around $0.25,0.5$ and 0.75 , respectively, and then builds and improves the corresponding dam failure consequences severity degree coefficient model.

Application example shows that the improved dam failure consequences severity degree coefficient model can 
objectively and reasonably determines the severity of the loss of life, economic losses, environmental impact, and social impact. The weight uses the analytic hierarchy process and considers different factors how to influence the comprehensive evaluation results, moreover, using linear weighting method to synthesize the severity of the four factors, and the rationality of the results is further analyzed. Considering the comparison of the gap between individual data of the loss of life, economic losses, environmental impact, social impact of the five reservoirs and the weight of the four factors, the rank results obtained by objective analysis are more consistent. Its evaluation process is clear, the calculation results are reasonable and credible, and it can be used as the reference for the evaluation results of other methods.

The improved model in this paper has carried out a comprehensive evaluation and rationality analysis of the consequences of dam failures of five reservoirs in Jiangxi. It has not analyzed the comprehensive evaluations of other regions and even more reservoirs after the dam failure. However, due to the complexity and diversity of actual projects, it may be difficult to unify the standards for the division of risk areas. It is hoped that the improved model can be verified through more actual cases in the later period, and it can be further improved.

\section{Fund Projects}

Fund projects of Nanjing Hydraulic Research Institute (Y720009) "Regulatory framework and technical standard system of reservoir dam safety management based on risk theory", and (Y719010) "Uncertainty analysis of flood simulation of earth-rock dam overtopping".

National Key R\&D Program of China Project (2018YFC0407104) "Key technologies for dam safety diagnosis and early warning based on big data", and (2018YFC0407106) "R\&D and application of national dam safety supervision cloud service platform".

\section{References}

[1] Rz Wang, L Li, Jb Sheng, et al. The model application research report on sort of reinforcement of dangerous reservoirs [R]. Nanjing: Nanjing Hydraulic Research Institute, 2005.

[2] LI Shou-yi, HE Guan-jie, XIA Ke, et al. A comprehensive hazard assessment model for the consequence to be caused by the dam collapse based on the theory of variable fuzzy sets [J] Journal of Safety and Environment, 2019, 19 (01): 7-13.

[3] Chen Yue, Gu Chongshi. Dam Break Consequences Assessment Model Based on Risk Matrix and Borda Ordinal Value Method [J] Journal of China Three Gorges Univ. (Natural Sciences), 2019, 41 (5): 1-5.
[4] LI Zongkun, LI Qi, GE Wei, et al. Comprehensive Assessment of Dam Risk Consequences Caused by the Dam Failure Based on the Set Pair Analysis [J] YELLOW RIVER, 2016, 38 (9): 111-114.

[5] LI Lei, WANG Ren-zhong, SHENG Jin-bao. Study on evaluation models of severity degree of dam failure impact $[\mathrm{J}]$ Journal of Safety and Environmen, 2006, 6 (01): 3-6.

[6] LI Gen, CHENG Yu-liang, YAN Shi-jia, et al. A comprehensive evaluation study on the degree of water conservancy modernization based on hierarchical analysis and fuzzy comprehensive evaluation $[\mathrm{J}]$ Water Resources Development Research, 2019, 216 (06): 67-71.

[7] GUO Tao, ZHANG Wen-hai, WU Liang, et al. Seismic Safety Evaluation of Concrete Gravity Dam considering multi-index influence factors $[\mathrm{J}]$ Journal of Vibration Engineering, 2020, 033 (001): 196-205.

[8] YANG Dianqing, HAN Qingyun. Fuzzy Multi-Index Comprehensive Evaluation Model of Online Public Opinion Situation Grades Based on TOPSIS Method [J] Journal of System Science and Mathematical Science, 2020, 40 (8), 1352-1364.

[9] YUE Lizhu, XU Ke, SHI Guang lei. Property Analysis and Method Selection of the Indexes Being Dimensionless [J] Statistics \& Information Forum, 2020, 035 (006): 3-9.

[10] Zk Shi. Linear system theory [M]. Beijing: Science Press, 2008.

[11] Li, Rz Wang, Jb Sheng, et al. Dam Risk Assessment and Risk Management [M]. China Water Conservancy and Hydropower Press, 2006: 86-95.

[12] L Li, Rz Wang, Jb Sheng. "Study on evaluation models of severity degree of dam failure impaet" [J]. Journal of safety and environment, 2006 (1), pp, 1-4.

[13] Rz Wang, L Li, Jb Sheng. "The research on risk standard system of dangerous reservoirs" [J]. Advances in Science and Technology of Water Resources, 2005, pp, 25 (5): 5-8.

[14] Rz Wang, L Li, Jb Sheng. "On criterion of social and environmentaJ risk of reservoir dams" [J]. Journal of safety and environment, 2006 (1), pp, 8-11.

[15] XIAO Xiang-jun. Research On Economic Loss Model of Environmental Carrying Capacity Caused by Flood and Waterlogging in Urban Tourism Areas [J] Journal of Catastrophology, 2020, 139 (04): 19-21+30.

[16] ZHENG Zhang-rong. Discussion on the exponential logarithm compound function formula of the water level-discharge relationship curve [J] Water Conservancy Technology 2020, 166 (01): 57-60.

[17] Kf Zhou. Study on analysis method of dam break life loss [D]. Nanjing Hydraulic Research Institute, 2006.

[18] Bj Zhang. Analytic hierarchy process and its application cases [M]. Electronic Industry Press, 2014. 